Original Article

\title{
ELECTROCHEMICAL AND CHEMOMETRIC DETERMINATION OF DORZOLAMIDE AND TIMOLOL IN EYE DROPS USING MODIFIED MULTIWALL CARBON NANOTUBE ELECTRODE
}

\author{
HASSAN A. M. HENDAWY1, HANAN M. ELWY1', AMANY M. FEKRY²
}

${ }^{1}$ National Organization for Drug Control and Research (NODCAR), P. O. Box 29, Cairo, Egypt, ${ }^{2}$ Cairo University, Faculty of Science, Department of Chemistry

Email: hanan18s@yahoo.com

Received: 23 Mar 2017 Revised and Accepted: 13 Jul 2017

\section{ABSTRACT}

Objective: This work is focused on the construction of simple and sensitive electrochemical sensor for quantitative determination of dorzolamide (DOR) and timolol maleate (TIM). This method is based on the incorporation of multiwall carbon nanotubes (MWCNT) into the carbon paste electrode which improve the characteristics of the electrode.

Methods: The electrochemical response of modified electrode was based on voltammetric oxidation, using cyclic voltammetry (CV) and impedance spectroscopy (EIS). The structural morphology of the surface modified electrode was characterized by scanning electron microscope (SEM). Quantitative analysis for each of the two compounds in a mixture has been examined by using of chemometric tools for resolving overlapping signals. The prediction performance of the chemometric method was analyzed by principal component regression (PCR) and partial least square (PLS).

Results: Fractional factorial design was constructed from set of synthetic mixtures of two drugs in concentration ranges of 0.05 to $1.6 \mu \mathrm{g} / \mathrm{ml}$ for DOR and $1.5-20 \mu \mathrm{g} / \mathrm{ml}$ for TIM. Under optimum experimental conditions, DOR and TIM gave rectilinear response over the concentration range of $0.072-1.88 \mu \mathrm{g} / \mathrm{ml}$ and $1.16-20.84 \mu \mathrm{g} / \mathrm{ml}$, respectively. The limit of detection (LOD) was found to be 0.098 and $1.025 \mu \mathrm{g} / \mathrm{ml}$, for DOR and TIM, respectively. It found that the $\%$ of relative prediction error (RPE) was acceptable and satisfactory.

Conclusion: In these work, for the first time, a new voltammetric simultaneous method developed for a rapid and efficient determination of DOR and TIM from eye dropper sample at nano modified electrode with satisfactory results. These results indicate that MWCNT holds great promise in practical application.

Keywords: Dorzolamide, Timolol, Square-wave voltammetry, Partial least squares, Chemometric

(C) 2017 The Authors. Published by Innovare Academic Sciences Pvt Ltd. This is an open access article under the CC BY license (http://creativecommons.org/licenses/by/4.0/] DOI: http://dx.doi.org/10.22159/ijpps.2017v9i9.18646

\section{INTRODUCTION}

Dorzolamide hydrochloride is a topical carbonic anhydrase inhibitor [1]. Inhibition of carbonic anhydrase-II decreases aqueous humor secretion. It is indicated for the reduction of elevated intraocular pressure in patients with open-angle glaucoma or ocular hypertension who are insufficiently responsive to beta blockers. Timolol maleate (TIM) is a non-selective beta adrenergic receptor blocker [2]. It is used to treat open-angle and occasionally secondary glaucoma through blockage of the beta receptors on the ciliary epithelium. Both DOR and TIM are used to lower pressure inside the eye by decreasing the production of natural fluids. The combined mixture of timolol maleate and dorzolamide hydrochloride is most advantageous than monotherapy. Their chemical structures are shown in Scheme 1.

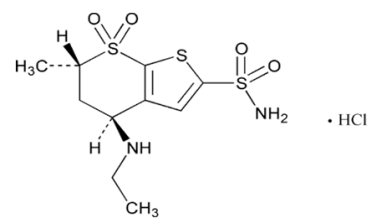

(a)

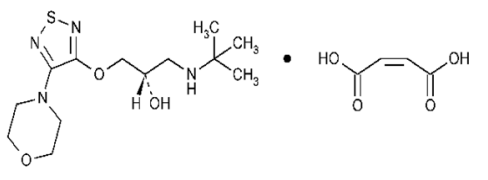

(b)

Scheme 1: Chemical structures of (a) dorzolamide hydrochloride, [1], (b) timolol maleate [2]
The literature survey reveals that both dorzolamide hydrochloride and timolol maleate have been analyzed by various techniques. Several methods have been reported for the determination of DOR and TIM in biological fluids [3-6] by HPLC [7-10], spectrophotometry [11-13], capillary electrophoretic (CE) [14], and there are some methods reported for estimation of DOR in pharmaceutical formulations [8,15-16]. Electrochemical detection is a very elegant method in the pharmaceutical analysis due to its high sensitivity, rapid response. Recently, CNTs are widely used in many types of sensors for determination of many compounds [17, 18]. CNTs are porous materials that offer high effective surface area, mass transfer, high electrical conductivity, and strong adsorption capacity resulting in increased sensitivity of sensors [19]. Thus, CNTs can powerfully enhance electron transfer reaction and improve sensitivity in electrochemistry. Consequently, CNTs have been explored as the most popular nano material used to prepare modified electrodes in the electro-analysis. Specially, the multiwall carbon nanotubes (MWCNTs) were thought to have much higher stability against electro-migration than other small metallic structures. MWCNT promote an effectual electronic transfer and are widely used in electro analytical chemistry for the sensitive detection of pharmaceutical compounds. Generally, there are two methods to prepare modified CNTs-based electrodes, in the first method, the CNTs is suspended on the surface of the solid electrodes, such as Pt and Au to make CNTs film modified electrodes [20-22]. The second method depends on mixing the CNTs with bonds such as mineral oil or nujol [23], to prepare modified paste electrodes. Differential pulse voltammetry (DPV) and square wave voltammetry (SWV) are widely used techniques in electrochemistry [24]. No electrochemical methodologies have been studied for simultaneous estimation of DOR and TIM, probably due to their similar electrochemical responses showing overlapping signals when using conventional electrodes. Due to the applicability of SWV 
is handiapped when overlapping of peaks is high. Therefore, the analysis of voltammetric data for these signals is difficult and direct determination of analytes with overlapping voltammogram peaks is impossible. So recently, chemometric methods such as the multivariate curve resolution and partial least squares (MCR-PLS) [25-27] have been applied for the analysis of binary and multi components with overlapping results. The main advantages of these techniques are the higher speed processing data concerning the values of concentrations and voltammograms of compounds with strong overlapping. Our objective in the present work was to develop a new voltammetric method for a rapid and efficient determination of DOR and TIM in the ophthalmic pharmaceutical formulation using MWCNT modified carbon paste electrode.

\section{MATERIALS AND METHODS}

\section{Chemicals and reagents}

All reagents were of analytical grade and used without further purification. DOR and TIM standard supplied from National Organization for Drug Control and Research NODCAR, acetazolamide obtained from local market. Britton-Robinson (BR) buffer $0.04 \mathrm{M}$ [28] was prepared by mixing an adequate amount of $0.2 \mathrm{M} \mathrm{NaOH}$ with different volumes of $0.04 \mathrm{M}$ each of $\mathrm{H}_{3} \mathrm{PO}_{4}, 0.04 \mathrm{M}$ acetic acid and $0.04 \mathrm{M}$ boric acid to obtain $\mathrm{pH}$ values varied from 2 to 10 . Graphite powder (particle dimension $20 \mu \mathrm{m}$ ) and MWCNTs (purified to more than $95 \% \mathrm{C}$ with a diameter of $6-9 \mathrm{~nm}$ and length of $5 \mu \mathrm{m}$ ) were obtained from Sigma (Egypt).

\section{Standard solutions and working solutions}

Stock solution of DOR and TIM (1.0 mg ml-1) was prepared in bidistilled water and stored in a refrigerator at $4^{\square} \mathrm{C}$. Standard working solutions prepared daily by serial dilution of the stock standard solution.

\section{Apparatus}

All voltammetric measurements were performed using Metrohm electro analyzers model 797VA Computrace. These measurements were recorded by using VA Computrace version 1.3.1. The one compartment cell with the three electrodes consisted of the working electrode; a platinum wire was used as the auxiliary electrode. All the cell potentials were measured with respect to $\mathrm{Ag} / \mathrm{AgCl}(3 \mathrm{M} \mathrm{KCl})$ reference electrode. Electrochemical impedance spectroscopic (EIS) measurements are performed using SP-150 potentiostat supplied with EC-Lab® software package. The impedance designs were recorded at the peak potential by applying $10 \mathrm{mV}$ sinusoidal potential through a frequency range of $1.0 \mathrm{mHz}$ to $100 \mathrm{kHz}$. A JENWAY $3510 \mathrm{pH}$ meter with a glass combination served to carry out the $\mathrm{pH}$ measurements. All experiments were carried out at room temperature of $25 \pm 0.1^{\square} \mathrm{C}$, repeated for 3 times and reproducible results were obtained.

\section{Preparation of carbon paste and MWCNT modified electrode}

The unmodified Carbon paste electrode was prepared by mixing graphite powder $0.225 \mathrm{~g}$ with paraffin oil (seven to eight drops, $\sim 0.2$ $\mathrm{ml}$ ) in a mortar. The carbon paste was packed into the hole of the electrode body and smoothed on a filter paper until its shiny appearance. The modified electrode was prepared by mixing graphite powder $(0.465 \mathrm{~g})$ and MWCNT $(0.035 \mathrm{~g})$ were mixed well for 10 min with an appropriate amount (seven to eight drops, 0.2 $\mathrm{ml}$ ) of paraffin oil as pasting liquid in a mortar and wetted paste was obtained $[29,30]$. The carbon paste was packed into the hole of the insulin syringe body with diameter $3.0 \mathrm{~mm}$. A new surface was obtained by removing excess paste out of the syringe tip and smoothed with a weighing paper until it has shiny appearance. Electrical contact was prepared by pushing a copper wire down into the syringe.

\section{Analytical procedure}

The prepared modified electrode with MWCNTs was activated in a $0.04 \mathrm{M}$ BR buffer as supporting electrolyte solution by CV sweeps between $0.0 \mathrm{~V}$ and $+1.3 \mathrm{~V}$ potential range with a scan rate of 100 $\mathrm{mVs}^{-1}$ until stable voltammograms were obtained $(\mathrm{n}=10)$. When the current became steady, the modified electrode surface was washed with distilled water. After each set of measurements, the electrode surface modified with MWCNTs was regenerated by successive cyclic voltammograms $(n=10)$ in the supporting electrolyte solution to remove charge impurities.

\section{Chemometric methods}

Chemometrics methods have played a vital role in facilitating the simultaneous analysis, PCR and PLS are factor analysis multivariate statistical tools which have many benefits and have been applied for analysis of multicomponent mixtures. In this paper only outline of the two chemometric methods will be provided.

\section{Calibration and validation sets}

A calibration set was outlined according to a fractional factorial design at several levels. PCR and PLS multivariate calibration methods involve constructing of the calibration set including a series of two drugs mixtures at five concentration levels. A calibration training set of twenty-five standard solutions was prepared in the concentration range of $0.05-1.6$ and $1.5-20 \mu \mathrm{g} / \mathrm{ml}$ for DOR and TIM, respectively. The concentration set and its composition was presented in (table 4).

\section{Model efficiency estimation}

A model can be applied for analysis of mixture samples or not, model validation is potentially the common critical stride in the model building sequence. In order to estimate the performance of models, validation of each model was investigated for the prediction of validation and test sets, The relative root mean square error (\%RMSE) was calculated for the models developed by using 3-5 latent variables for the calibration (\%RMSEC), the prediction (\%RMSEP) sets, and relative error of prediction (REP), for both DOR and TIM, respectively.

$$
\begin{aligned}
& \text { RMSEP }=\frac{\sqrt{\sum_{1}^{\mathrm{n}(\text { Ypred }- \text { Yact }) 2}}}{\mathrm{n}} \\
& \operatorname{REP}(\%)=\frac{100 * \sqrt{\frac{1}{\mathrm{n}} \sum_{\mathrm{i}=1}^{\mathrm{n}}(\text { Ypred }- \text { Yact }) 2}}{\text { Ymean }}
\end{aligned}
$$

Where yact and ypred are actual and predicted concentrations of each component, respectively, and $\mathrm{n}$ is the number of samples in validation or test set.

\section{RESULTS AND DISCUSSION}

Carbon paste electrodes have several advantages of very low Ohmic resistance, low cost, very short response time, reproducibility of the preparation process, simplicity, cheap and quick preparation process which provide the possibility of measurements on small volumes. Therefore, the goal of this article is a fabrication of novel modified carbon paste electrodes for the determination of DOR and TIM in a pharmaceutical preparation.

\section{Morphology of the different electrodes \\ Scanning electron microscope (SEM)}

The SEM images of both CPE and MWCNT modified electrode are shown in fig. 1. The response of an electrochemical sensor was related to its physical morphology. Significant differences are observed in the surface structure of the two electrodes. The SEM image of the bare CPE is irregularly shaped graphite flakes and separated layers. While, the SEM image of MWCNT modified electrode shows flowery shaped SEM with a physical appearance and surface characteristics of, most of the particles homogeneously dispersed on the electrode's surface. This flowery like structure; displays a high surface area as shown in fig. 1 .

\section{Impedance of CPE and MWCNT modified}

Impedance plots are shown as Nyquist plots (fig. 2 inset) for both the Bare and modified electrodes. It shows a semicircle corresponds to a charge transfer resistance at high frequency and a line corresponds to a diffusion process at low frequencies, respectively. The best model used to fit the experiments (fig. 2 inset) is a two time 
constant model consists of $R_{s}$ (solution resistance), $R_{1}, R_{2}$ (resistances of inner and outer layers, respectively), [31] W (Warburg impedance) and $\mathrm{C}_{1}, \mathrm{C}_{2}$ (capacitances of inner and outer layers, respectively). The data simulated to this equivalent circuit with a reasonable fit ( $2 \%$ average error). $\mathrm{W}$ is related to the linear region at low frequency (diffusion process) [32, 33], $R_{1}, R_{2}$ are related to the semicircle at high frequency (charge transfer resistances of inner and outer layers, respectively). So, the mechanism of the reaction depends on both charge transfer and diffusion process. The fitting performed using EC-Lab® software [32, 34-36]. The impedance fitting parameters for the two electrodes are listed in (table 1). The MWCNT electrode shows a higher value for the inner capacitance $(1.7 \mu \mathrm{F})$, Warburg impedance (315.1 $\Omega \mathrm{s}$ $1 / 2)$ and lower values for the charge transfer resistance $(1500 \Omega)$ indicating a higher conductivity compared to the bare electrode $(3000 \Omega)$. These results approve well the highest oxidation peak current obtained from CV's results to MWCNT electrode.

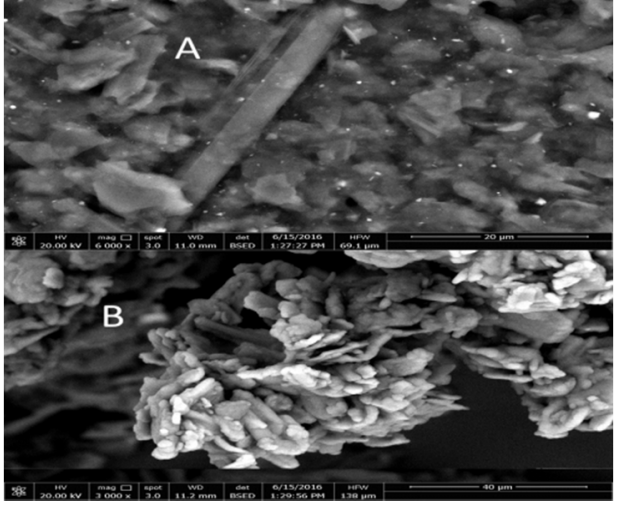

Fig. 1: SEM images of MWCNT (A) and CPE (B) electrodes

Table 1: Fitting parameters for bare and CNT electrodes

\begin{tabular}{|c|c|c|c|c|c|c|}
\hline Electrode & $\mathbf{R}_{\mathbf{s}}\left(\boldsymbol{\Omega}_{\left.\mathrm{cm}^{2}\right)}\right.$ & $C_{1\left(\mu \mathrm{Fcm}^{-2}\right)}$ & $R_{1}\left(\Omega_{\left.\mathrm{cm}^{2}\right)}\right.$ & $\mathrm{C}_{2\left(\mu \mathrm{Fcm}^{-2}\right)}$ & $\mathbf{R}_{2}\left(\boldsymbol{\Omega}_{\mathrm{cm}^{2}}\right)$ & $W\left(\Omega_{\left.\mathrm{cm}^{2} \mathrm{~s}^{1 / 2}\right)}\right.$ \\
\hline Bare CPE & 400 & 0.4 & 3000 & 2.2 & 500 & 111 \\
\hline MWCNT & 320.8 & 1.7 & 623 & 3.1 & 121.5 & 315.1 \\
\hline
\end{tabular}

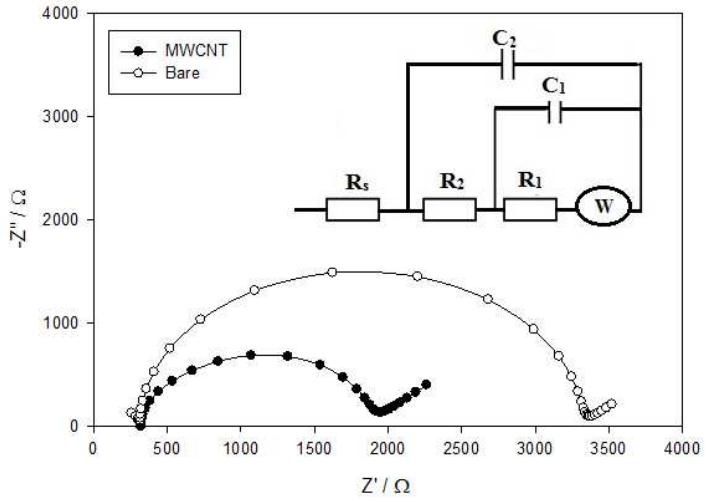

Fig. 2: Nyquist plots for both bare and MWCNT electrodes. Inset: Two time constant equivalent circuit model including Warburg diffusion impedance

\section{Electrochemistry of dorzolamide $\mathrm{HCl}$ and timolol maleate}

The voltammetric behavior of DOR and TIM in B-R buffer $\mathrm{pH} 6$ at a scan rate $100 \mathrm{mVs}^{-1}$ displayed a well-defined irreversible oxidation peak, and no reduction signal was observed in the reverse scan. The addition of MWCNT in the matrix of CPE was examined by comparing the voltammetric response of electrode. The sensitivity of the modified electrode was higher than bare electrode; it causes the increase of anodic peak current. The enhancement in current was attributed to the larger surface area of the modified electrode that improves the conductivity of the electrode. The suggested oxidation mechanism of DOR and TIM was presented in scheme 2 .

\section{Effect of $\mathbf{p H}$}

The influence of $\mathrm{pH}$ on the electrocatalytic oxidation of DOR and TIM was studied at the modified CPE using B-R buffer within $\mathrm{pH}$ range 310. It was observed that the oxidation peak potential shifted negatively with the increase in $\mathrm{pH}$ values that confirm the suggested mechanism in scheme 2. As depicted in fig. 3 the anodic peak potentials shifted gradually to less positive values with the increase in the solution $\mathrm{pH}$, indicating the involvement of protons in the oxidation reactions. The highest oxidation current was observed at $\mathrm{pH} 6.0$ for both DOR and TIM analysis. It was selected as the optimum $\mathrm{pH}$ for the determination of both drugs. The relation between peak potential and $\mathrm{pH}$ lead to a linear regression equations $\mathrm{Ep}(\mathrm{V})=1.4877-0.0603 \mathrm{pH}\left(\mathrm{R}^{2}=0.9827\right)$ for $\mathrm{DOR}$

$\mathrm{Ep}(\mathrm{V})=1.0885-0.0286 \mathrm{pH}\left(\mathrm{R}^{2}=0.9538\right)$ for TIM.

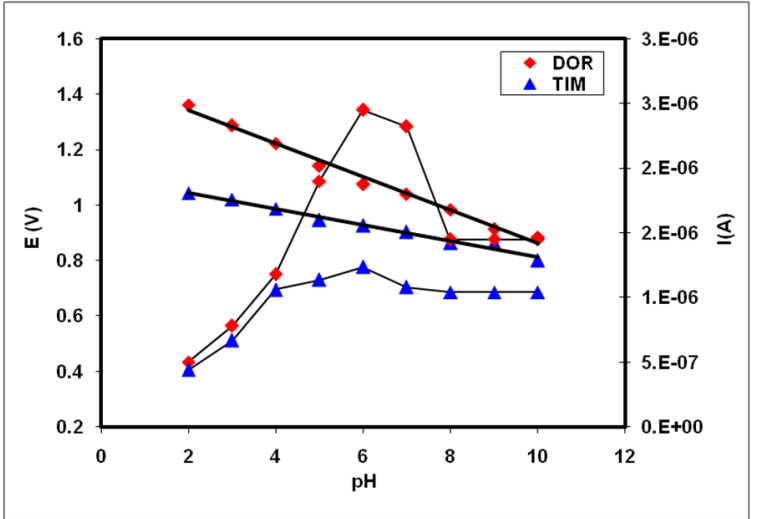

Fig. 3: Effect of $\mathrm{pH}$ on the peak potential for mixture solution of $20 \mathrm{mmol}$ DOR and10 mmol TIM in 0.04M BR at pH 6 at MWCNT modified electrode with scan rate of $100 \mathrm{mV} \mathrm{s}^{-1}$

The result shows, that the slopes of DOR and TIM were- 0.0603 and$0.028 \mathrm{~V}$, respectively, [37] indicated that the system obeys Nernest equation. These results revealed that an equal number of participated protons and transferred electrons are involved in the oxidation case of DOR but not the same number in TIM. The proposed mechanism was a loss of lone pair of electrons for amine group with losing of two protons in the oxidation of DOR and loss of one electron in the case of TIM as depicted in scheme 2.

A<smiles>CC=NC1CC(C)S(=O)(=O)c2sc(S(N)(=O)=O)cc21</smiles>

B<smiles>CC(C)(C)NC[C@H](O)COc1nsnc1N1CCOCC1</smiles>

Scheme 2: Proposed oxidation mechanisms for the two drugs at MWCNT modified electrode 


\section{Effect of scan rate}

Scan rate is one of the most important factors affecting the behaviour of electrochemical mechanism and kinetic of the cited drugs. The peak current grows with increasing scan rates, and plot of Ip versus $v^{1 / 2}$ gave linear relationships between the peak currents and the square root of the scan rate $\left(v^{1 / 2}\right)$.

The oxidation peak potential shifts with increasing scan rates toward a more positive potential, indicating that oxidation process is irreversible. Scan rates were also studied to evaluate whether the process on MWCNT electrode was underneath diffusion or adsorption controlled. With increasing scan rate, the oxidation peak current of DOR and TIM increased, the relation of the square root of scan rate with the peak height of current exhibit a linear relationship in the range of $10-110 \mathrm{mV} / \mathrm{s}$ fig. 4 which represents a typical diffusion controlled process and equation can be expressed by

$\mathrm{I}(\mathrm{A})=27.322 \mathrm{v}^{1 / 2}+0.2038 \mathrm{R}^{2}=0.994(\mathrm{DOR}), \mathrm{I}(\mathrm{A})=39.341 \mathrm{v}^{1 / 2}+0.2835$ $\mathrm{R}^{2}=0.996$ (TIM)

Suggesting that the reaction is diffusion-controlled electrode reaction [38].

Linear calibration plot of single component and limit of detection

The SWV responses were studied at pH 6.0 on the MWCNT for a concentration range from $0.072-1.881$ and $1.6-20.84 \mu \mathrm{g} / \mathrm{ml}$ of DOR and TIM, respectively, as shown in fig. 5( $\mathrm{a}$ and $\mathrm{b}$ ). In addition to the parameters of the calibration, the following conditions are used: voltage step $2 \mathrm{mV}$, amplitude $20 \mathrm{mV}$ and frequency $50 \mathrm{~Hz}$. Linear regression equation between Ip and concentration of drug can be expressed by the following equations: $\mathrm{Ip}=1.8053 \mathrm{C}+0.1262,\left(\mathrm{R}^{2}=\right.$ $0.9950), \mathrm{Ip}=0.0814 \mathrm{C}+0.2966,\left(\mathrm{R}^{2}=0.9976\right)$, for DOR and TIM, respectively, the limits of detection (LOD) were found to be 0.017 and 0.932 for DOR and TIM, respectively. The relative parameters are summarized in (table 2).

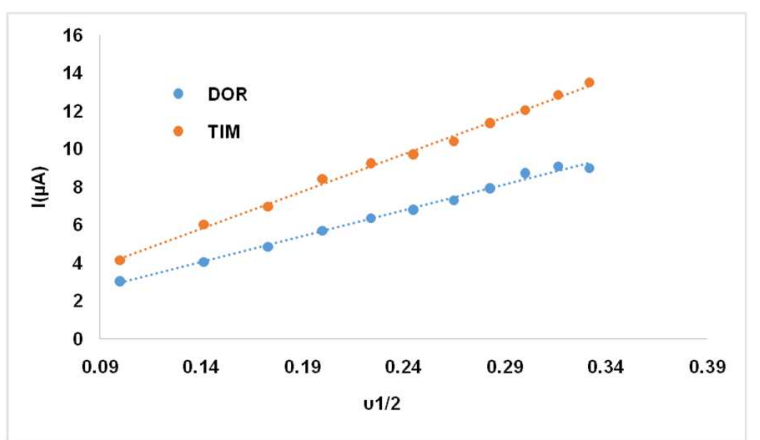

Fig. 4: linear relation between the anodic peak current of DOR, TIM and the square root of the scan rate $\left(\mathrm{mVs}^{-1}\right)$ at $\mathrm{pH} 6.0$ for MWCNT with different scan rates (10-100 $\left.\mathrm{mVs}^{-1}\right)$

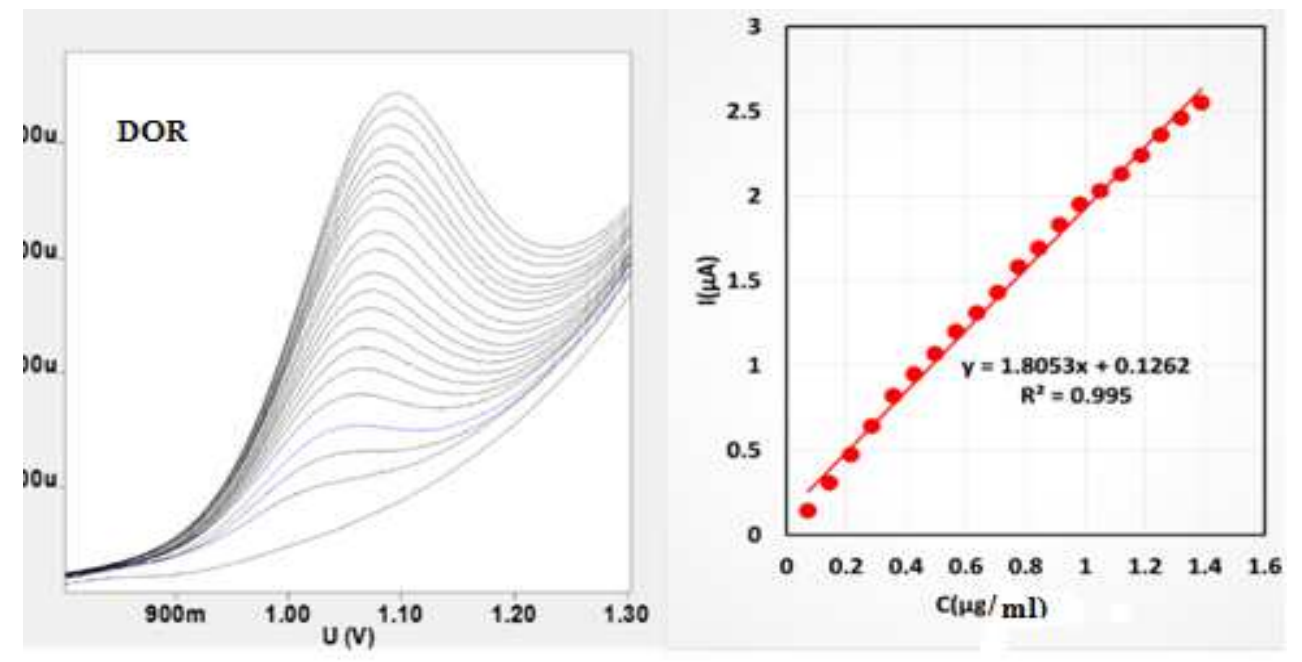

2.5
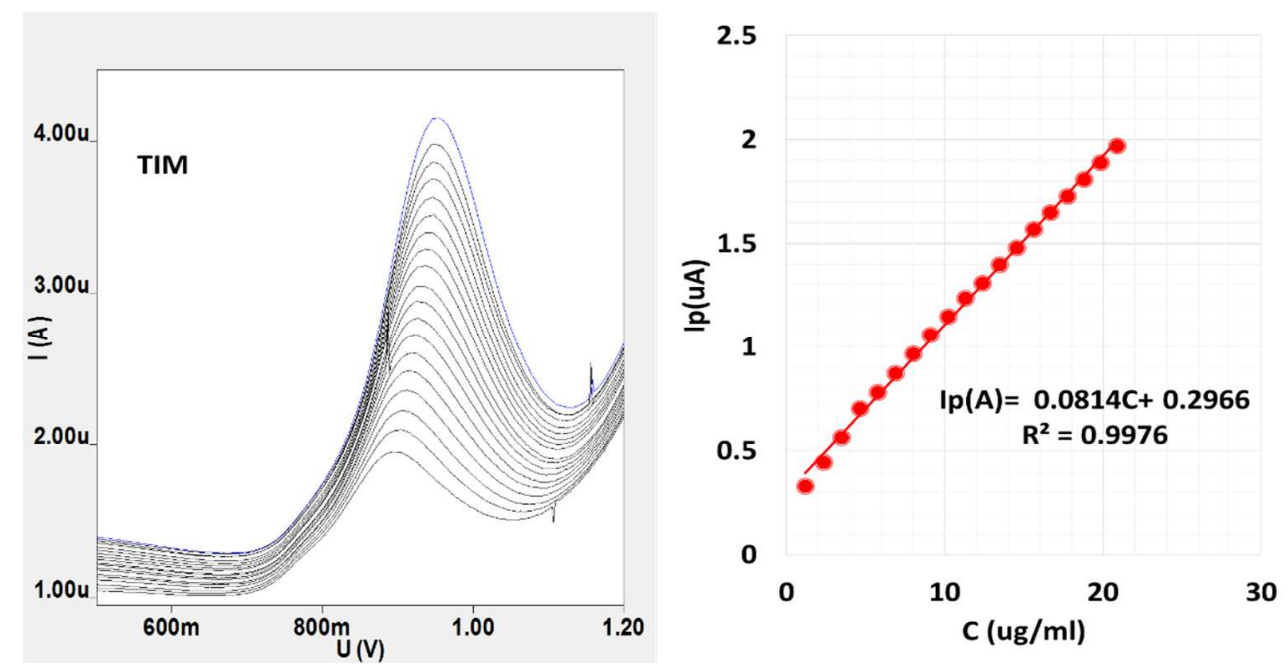

Fig. (5a, b): Square-wave voltammograms for calibration of DOR and TIM at pH 6.0 on the MWCNT from insert corresponds to the analytical curves obtained from voltammograms 
Table 2: The parameters of linear calibration equation for each drug analyte

\begin{tabular}{lll}
\hline Parameter & TIM & DOR \\
\hline Linear range $(\mu \mathrm{g} / \mathrm{ml})$ & $1.16-20.84$ & $0.072-1.88$ \\
Intercept $(\mathrm{a})$ & 0.2966 & 0.1262 \\
Slope $(\mathrm{b})$ & 0.0814 & 1.8053 \\
Correlation coefficient $\left(\mathrm{R}^{2}\right)$ & 0.9976 & 0.995 \\
Sa & 0.0302 & 0.122 \\
Sb & 0.0253 & 0.01 \\
Detection limit $(\mu \mathrm{g} / \mathrm{ml})$ & 0.932 & 0.017 \\
\hline
\end{tabular}

Sa: Standard deviation of the intercept, $S \mathrm{~b}$ : Standard deviation of the slope.

\section{Effect of SWV}

A study for Inferable from high affect ability and transcendent detachment properties from background current, SWV utilized to examine the dependencies relation between peak currents of DOR and TIM and their concentrations. The improvement of this system incorporates an advancement of instrumental parameters that influence current response of both drugs, such as pulse amplitude, frequency and step increment. These parameters interrelate and influence the peak current. In a way that every parameter was changed while the others were kept constant. It was found that the peak currents of DOR and TIM increased simultaneously with the increasing of pulse amplitude from 10 to $140 \mathrm{mV}$ joined by the widening peak widths at the same time. At the point when the pulse amplitude was higher than $60 \mathrm{mV}$, both oxidation peaks became much wider fig. 6.

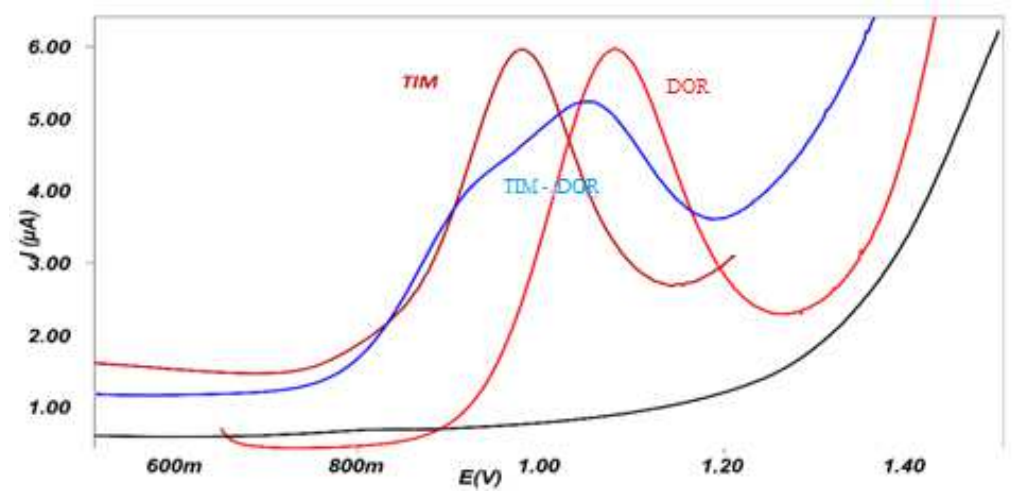

Fig. 6: Square wave voltammetric curves of $20 \mathrm{mmol}$ DOR and $20 \mathrm{mmol}$ TIM and for mixture solution $20 \mathrm{mmol}$ DOR and $15 \mathrm{mmol}$ TIM in $0.04 \mathrm{M}$ BR at $\mathrm{pH}=6 \mathrm{buffer}$ at MWCNT modified electrode

Quantitative analysis of individual drug was studied using SWV. The effect of the experimental parameters that affect the SWV response was evaluated for square wave voltammetric curves of $20 \mathrm{mmol}$ DOR and $20 \mathrm{mmol}$ TIM and for mixture solution $20 \mathrm{mmol}$ DOR and $15 \mathrm{mmol}$ TIM in $0.04 \mathrm{M}$ BR at $\mathrm{pH}=6$ buffer at MWCNT modified electrode (fig. 6) The obtained optimum values for these parameters are presented in (table 2).

\section{Application of pharmaceutical formulations}

The validity of the proposed voltammetric method was assessed for the determination of DOR and TIM in their pharmaceutical preparations. The mean recovery values were 99.95 and $100.02 \%$ with RSD 0.068 and $0.031 \%$ for DOR and TIM, respectively. The results of the proposed method are compared with those obtained from the reference methods [39] applying the Student's t-test and F- test values did not exceed the theoretical values of 2.776 and 19 for $\mathrm{t}$-and F-tests, respectively, (table 3). This comparison indicated that the proposed methods is not only as accurate as the reference methods, but it use simple reagent and apparatus; it is also applicable to a wide range of concentration besides being timesaving. The calculated t values ( 0.612 for DOR and 0.299 for TIM) were smaller than $t$ Tabulated (2.776). The results are listed in (table 3). Hence, the proposed voltammetric method is adequate for the simultaneous determination of DOR and TIM in pharmaceutical formulations. The results suggested that MWCNT has high reproducibility and would be a useful sensor for quantitative analysis DOR and TIM. The robustness was examined by evaluating the variation of $\mathrm{pH} 6.5$ instead of $\mathrm{pH}$ 6. The obtained results indicated that the proposed procedures for DOR and TIM assay can be considered robust.

Table 3: Application of the proposed and comparison methods for determination of DOR and TIM in its pharmaceutical preparations

\begin{tabular}{lllll}
\hline Dosage form & DOR & TIM & Ref. method ${ }^{\text {OR }}$ [39] & Ref. method $^{\text {TIM }[39] ~}$ \\
\hline Cosopt® dropper & 99.8 & 100.03 & 99.98 & 99.97 \\
Found \% & 100.1 & 99.97 & 99.95 & 100.1 \\
& 99.95 & 100.08 & 100.1 & $100.02 \pm 0.04$ \\
mean \pm SE & $99.95 \pm 0.086$ & $100.03 \pm 0.031$ & $100.01 \pm 0.046$ & \\
Standard Deviation & 0.15 & 0.55 & & \\
Variance & 0.025 & 0.303 & & \\
t-test & 0.612 & 0.299 & & \\
F-test & 3.57 & 1.617 & & \\
t-Tabulated & 2.776 & & & \\
F-Tabulated & 19 & & & \\
\hline
\end{tabular}

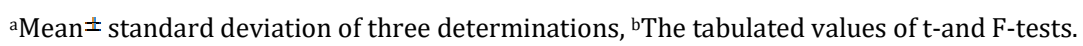


Comparisons of the data obtained for DOR and TIM determination using MWCPE with various methods, showed that our sensor is more sensitive than the reported HPLC methods: (120-480 and 360$1440 \mu \mathrm{g} / \mathrm{ml}$ ) [40], (40-120 and $10-30 \mu \mathrm{g} / \mathrm{ml})$ [41] and (2-20.5 and 4$45 \mu \mathrm{g} / \mathrm{ml}$ ) [8] for TIM and DOR, respectively.

\section{Prediction of synthetic mixtures of the drugs}

In this work, the quantitative analysis of drug mixtures by SWV and multivariate calibration methods of PCR, and PLS was investigated. A set of 25 calibration samples was prepared using concentration values commensurate with the linear range thresholds (table 4).

Table 4: Concentration data of calibration set (C 1-C 14), and test set (T 15-T 25)

\begin{tabular}{|c|c|c|c|c|c|}
\hline Sample & TIM $(\mu \mathrm{g} / \mathrm{ml})$ & DOR $(\mu \mathrm{g} / \mathrm{ml})$ & Sample & TIM $(\mu \mathrm{g} / \mathrm{ml})$ & DOR $(\mu \mathrm{g} / \mathrm{ml})$ \\
\hline C 1 & 20.0 & 0.83 & C14 & 20.0 & 1.60 \\
\hline C 2 & 10.8 & 0.05 & T 15 & 15.4 & 1.21 \\
\hline C 3 & 6.10 & 1.21 & T 16 & 20.0 & 0.05 \\
\hline C 4 & 6.10 & 0.44 & Т 17 & 1.50 & 1.21 \\
\hline C 5 & 20.0 & 1.21 & Т 18 & 20.0 & 0.44 \\
\hline C 6 & 6.10 & 0.05 & Т 19 & 15.4 & 0.83 \\
\hline C7 & 15.4 & 0.05 & Т 20 & 10.8 & 1.21 \\
\hline C8 & 10.8 & 0.83 & Т 21 & 1.50 & 1.60 \\
\hline C9 & 15.4 & 1.60 & Т 22 & 10.8 & 1.60 \\
\hline C10 & 10.8 & 0.44 & Т 23 & 6.10 & 0.83 \\
\hline C11 & 1.50 & 0.05 & Т 24 & 15.4 & 0.44 \\
\hline C12 & 1.50 & 0.44 & Т 25 & 1.50 & 0.83 \\
\hline $\mathrm{C} 13$ & 6.10 & 1.60 & & & \\
\hline
\end{tabular}

\section{Method validation}

Ten synthetic mixtures containing DOR and TIM in different concentrations levels were prepared as an independent validation set. The validation using PCR and PLS method has been done for obtaining reliable results of the analysis. The percentage recoveries and relative standard deviations were indicated in (table 5). The selection of the optimal number of latent variables for the PCR and PLS models is an essential step to avoid more noise added to the calibration model. A lot of methods are used for determining the optimal number of latent variables. In this study a cross-validation method was employed for the selection of the number of latent variables, using in the calibration set as in fig. 7 (a, b). A cross validation method leaving out one sample at a time was used. Anywhere selected samples are kept out of the calibration and used for prediction. This is repetitive till all samples have been kept out once. Validation residual variance can then be calculated from the prediction residuals. In segmented cross validation, the samples are divided into sub categories or "segments". One segment at a time is kept out of the calibration. There are as many calibration series as segments so that predictions can be investigated on all samples. The application of PCR and PLS models for prediction was quite successful. In mixtures containing both drugs, the relative mean error (RME) values were less than $10 \%$ and the recoveries were close to $100 \%$; these recoveries were acceptable being in the range of $97.5-100.4 \%$. The PCR and PLS models were applied to the drug mixtures in this study. The root means squares error of crossvalidation (RMSECV) was computed as an investigative test for inspecting the errors in the predicted applications. Five and three LVs were found suitable for PCR and PLS, respectively, as in fig. 7 (a, b). The results predicted by the multivariate methods for the training set model are summarized in (table 5).

\section{Interference studies}

Under the experimental optimum conditions, potential interferences such as ions and organic compounds are investigated by addition of possible interference traces to mixture solution containing $20 \mathrm{mmol}$ DOR and TIM. It was found that the common ions such as $\mathrm{Na}^{+}, \mathrm{Pb}^{+2}$, $\mathrm{SO}_{4}{ }^{-2}, \mathrm{CO}_{3}{ }^{-2}$ and $\mathrm{NO}_{3}$ had no interfere with DOR and TIM. No interfering peaks have been recorded around the peak potentials of DOR and TIM in 60-fold excess of common urinary compounds such as glucose, uric acid and ascorbic acid (signal change below 5\%). As an illustrated example, we observe that uric acid oxidized at +0.5 to+0.7 $\mathrm{V}$ according to $\mathrm{pH}$ value. These facts prove the good selectivity of the proposed method and offer the promising possibilities for simultaneous determination of DOR and TIM.
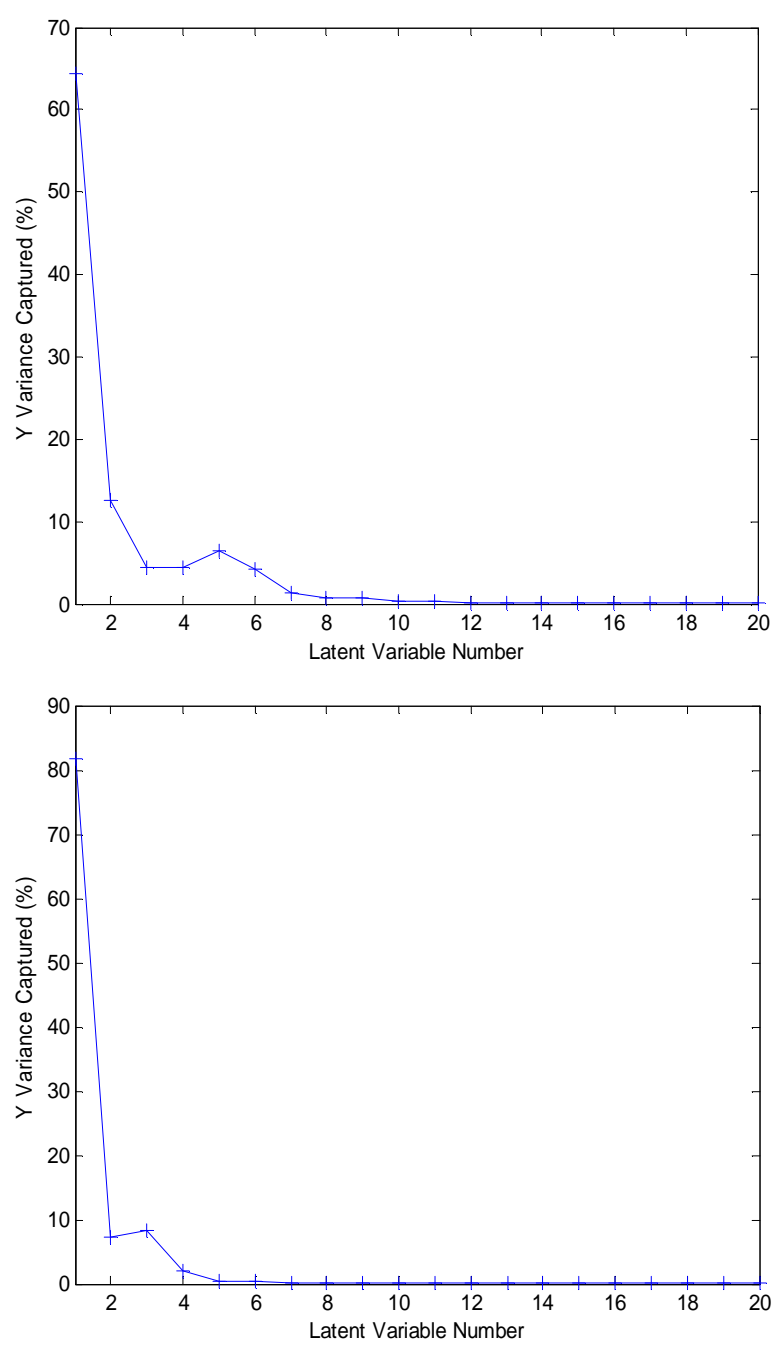

Fig. 7: RMSEC plot of the cross validation results of the calibration set as a function of the number of latent variables used to construct the PCR (a)and PLS (b)calibration 
Table 5: Recovery results obtained for the synthetic mixtures for PCR and PLS methods

\begin{tabular}{|c|c|c|c|c|c|}
\hline & \multirow{2}{*}{\multicolumn{2}{|c|}{ Recovery (\%) }} & \multicolumn{2}{|c|}{ Recovery (\%) } \\
\hline \multicolumn{2}{|c|}{ Mixtures added $(\mu \mathrm{g} / \mathrm{ml})$} & PCR & & PLS & \\
\hline DOR & TIM & DOR & TIM & DOR & TIM \\
\hline 15.4 & 1.21 & 96.96 & 96.85 & 99.47 & 99.14 \\
\hline 20 & 0.05 & 98.99 & 105.71 & 101.8 & 102.01 \\
\hline 1.5 & 1.21 & 85.73 & 118.57 & 100.71 & 99.09 \\
\hline 20 & 0.44 & 102.98 & 103.08 & 99.45 & 98.51 \\
\hline 15.4 & 0.83 & 102.99 & 104.07 & 97.50 & 98.44 \\
\hline 10.8 & 1.21 & 89.67 & 88.96 & 99.49 & 102.62 \\
\hline 1.5 & 1.6 & 109.9 & 108.2 & 102.48 & 100.09 \\
\hline 10.8 & 1.6 & 99.73 & 93.59 & 101.28 & 102.34 \\
\hline 6.1 & 0.83 & 97.18 & 91.43 & 99.50 & 102.30 \\
\hline 15.4 & 0.44 & 89.51 & 95.37 & 102.54 & 101.92 \\
\hline 1.5 & 0.83 & 98.87 & 95.97 & 98.77 & 98.07 \\
\hline Mean & & 97.5 & 100.16 & 100.27 & 100.41 \\
\hline RSD\% & & 2.1 & 2.61 & 1.54 & 1.74 \\
\hline RMSECV & & 0.417 & 0.087 & 0.45 & 0.046 \\
\hline RMSEP & & 0.560 & 0.013 & 0.60 & 0.70 \\
\hline
\end{tabular}

\section{CONCLUSION}

In the present paper, the electrochemistry combined with chemometrics tools has been developed an effective method for simultaneous determination of DOR and TIM. The two drugs exhibited a similar anodic behaviour; all are of irreversible character and $\mathrm{pH}$-dependent. A strong and dramatic voltammetric overlapping observed for the simultaneous determination of these drug compounds when using suitable relabel electrodes. Chemometric tools PLS, PCR were successfully applied to resolve the overlapped voltammograms signals of these compounds in mixtures. It found that PLS and PCR improved the prediction results significantly, and yielded good REP values less than $10 \%$ for both the individual and overall estimates as well as good percentage recoveries. The proposed method applied successfully for the determination of the studied drugs in dosage forms without interference from excipients. The facts prove the good selectivity of the proposed method and offer the promising possibilities for simultaneous determination of DOR and TIM.

\section{ACKNOWLEDGMENT}

The authors are gratefully acknowledged to the Department of Physical Chemistry Faculty of Science, Cairo University, and National Organization for Drug Control and Research (NODCAR, Egypt) for providing instruments and the means necessary to accomplish this work.

\section{CONFLICTS OF INTERESTS}

All authors have none to declare

\section{REFERENCES}

1. The Merck Index. An encyclopedia of Chemicals, Drugs and Biological fourteen ed. Merck and Co., Inc; Whitehouse Station, NJ; 2006. p. 579.

2. The Merck Index. An encyclopedia of Chemicals, Drugs and Biological fourteen ed. Merck and Co., Inc; Whitehouse Station, NJ; 2006. p. 1623.

3. Constanzer M, Chavez C, Matuszewski B. Low-level determination of dorzolamide and its de-ethylated metabolite in human plasma by liquid chromatography with atmospheric pressure chemical ionization tandem mass spectrometry. J Pharm Biomed Anal 1997; 15:1001-8.

4. Maltese A, Bucolo C. Rapid high-performance liquid chromatographic assay of dorzolamide in rabbit aqueous humor. Biomed Chromatogr 2002;16:274-6.

5. Tim RC, Kautz RA, Karger BL. Ultratrace analysis of drugs in biological fluids using affinity probe capillary electrophoresis: Analysis of dorzolamide with fluorescently labeled carbonic anhydrase. Electrophoresis 2000;21:220-6.

6. Zammataro A, Saletti R, Civiale C, Muccilli V, Cunsolo V, Foti S. Simultaneous quantification of carteolol and dorzolamide in rabbit aqueous humor and ciliary body by liquid chromatography/atmospheric pressure chemical ionization mass spectrometry. J Chromatogr B 2010;878:807-14.

7. Dovletoglou A, Thomas SM, Berwick L, Ellison DK, Tway PC. Development of practical HPLC methods for analysis and quality assessment of the novel carbonic anhydrase inhibitor MK-0507 and the acetamidosulfonamide intermediate. J Liq Chromatogr Related Technol 1995;18:2337-52.

8. Erk N. Rapid and sensitive HPLC method for the simultaneous determination of dorzolamide hydrochloride and timolol maleate in eye drops with diode-array and UV detection. Die Pharm Int J Pharm Sci 2003;58:491-3.

9. Kanchan R, Roy SM, Rane R. Simultaneous RP-HPLC determination of dorzolamide hydrochloride and timolol maleate in pharmaceutical preparations. Trade Sci Inc 2008;7:126-7.

10. Novak T, Berwick L. Determination of the enantiomeric composition of a novel topically active carbonic anhydrase inhibitor by HPLC. J Liq Chromatogr Related Technol 1998;21:1883-96.

11. Bebawy LI. Application of TLC-densitometry, first-derivative UV-spectrophotometry and ratio derivative spectrophotometry for the determination of dorzolamide hydrochloride and timolol maleate. J Pharma Biomed Anal 2002;27:737-46.

12. Erk N. Simultaneous determination of dorzolamide HCL and timolol maleate in eye drops by two different spectroscopic methods. J Pharm Biomed Anal 2002;28:391-7.

13. Lotfy HM, Hegazy MA, Rezk MR, Omran YR. Novel spectrophotometric methods for simultaneous determination of timolol and dorzolamide in their binary mixture. Spectrochim Acta Part A 2014;126:197-207.

14. Palabiyik IM, Caglayan MG, Onur F. Multivariate optimization and validation of a CE method for simultaneous analysis of dorzolamide hydrochloride and timolol maleate in ophthalmic solution. Chromatographia 2011;73:541-8.

15. Erk N. Voltammetric and HPLC determination of dorzolamide hydrochloride in eye drops. Die Pharm Int J Pharm Sci 2003;58:870-3.

16. Sharath H, Jose GB, Channabasavaraj K, Modiya J. Development and validation of spectrophotometric methods for Estimation of dorzolamide HCL in bulk and pharmaceutical dosage forms. Int J Pharm Sci Res 2011;2:948-53.

17. Geto A, Pita M, De Lacey AL, Tessema M, Admassie S. Electrochemical determination of berberine at a multiwalled carbon nanotubes-modified glassy carbon electrode. Sens Act B: Chem 2013;183:96-101.

18. Song D, Xia J, Zhang F, Bi S, Xiang W, Wang Z, et al. Multiwall carbon nanotubes-poly (diallyldimethylammonium chloride)graphene hybrid composite film for simultaneous determination of catechol and hydroquinone. Sens Act B: Chem 2015;206:111-8.

19. Yanez-Sedeno P, Pingarron JM, Riu J, Rius FX. Electrochemical sensing based on carbon nanotubes. Trends Anal Chem 2010;29:939-53. 
20. Wang JX, Li MX, Shi ZJ, Li NQ, Gu ZN. Investigation of the electrocatalytic behavior of single-wall carbon nanotube films on an au electrode. Microchem J 2002;733:25-33.

21. Zeng B, Huang F. Electrochemical behavior and determination of fluphenazine at multiwalled carbon nanotubes/(3mercaptopropyl) trimethoxysilane bilayer modified gold electrodes. Talanta 2004;64:380-6.

22. Britto PJ, Santhanam KSV, Ajayan PM. Carbon nanotube electrode for oxidation of dopamine. Bioelectrochem Bioenerg 1996;41:121-5.

23. Rizk M, Abou El-Alamin MM, Hendawy HA, Moawad MI. Highly sensitive differential pulse and square wave voltammetric methods for determination of strontium ranelate in bulk and pharmaceutical dosage form. Electroanal 2016;4:770-7.

24. Shalaby A, Hassan WS, Hendawy HA, Ibrahim A. Electrochemical oxidation behavior of itraconazole at different electrodes and its anodic stripping determination in pharmaceuticals and biological fluids. J Electroanal Chem 2016;763:51-62.

25. Ni Y, Qiu P, Kokot S. Simultaneous determination of three organophosphorus pesticides by differential pulse stripping voltammetry and chemometrics. Anal Chim Acta 2004;516:7-17.

26. Asadollahi-Baboli M, Mani-Varnosfaderani A. Rapid and simultaneous determination of tetracycline and cefixime antibiotics by mean of gold nanoparticles-screen printed gold electrode and chemometrics tools. Measure 2014;47:145-9.

27. Gholivand MB, Jalalvand AR, Goicoechea HC, Gargallo R, Skov T. Chemometrics: an important tool for monitoring interactions of vitamin B7 with bovine serum albumin with the aim of developing an efficient biosensing system for the analysis of protein. Talanta 2015;132:354-65.

28. Britton HTS, Robinson RA. CXCVIII. Universal buffer solutions and the dissociation constant of veronal. J Chem Soc (Resumed) 1931;1456-62. Doi:10.1039/JR9310001456

29. Shehata M, Azab S, Fekry A, Ameer M. Nano- $\mathrm{TiO}_{2}$ modified carbon paste sensor for electrochemical nicotine detection using anionic surfactant. Biosens Bioelectron 2016;79:589-92.

30. Fekry AM. A new simple electrochemical moxifloxacin hydrochloride sensor built on carbon paste modified with silver nanoparticles. Biosens Bioelect 2017;87:1065-70.

31. Fekry AM. Electrochemical behavior of a novel nanocomposite coat on Ti alloy in phosphate buffer solution for biomedical applications. RSC Adv 2016;6:20276-85.
32. Fekry A, Ameer M. Electrochemical investigation on the corrosion and hydrogen evolution rate of mild steel in sulphuric acid solution. Int J Hydrog Energy 2011;36:11207-15.

33. Heakal FE-T, Fekry A. Experimental and theoretical study of uracil and adenine inhibitors in Sn-Ag alloy/nitric acid corroding system. J Electrochem Soc 2008;155:C534-C42.

34. Heakal FET, Fekry AM, Fatayerji MZ. Electrochemical behavior of AZ91D magnesium alloy in phosphate medium: part II. Induced passivation. J Appl Electrochem 2009;39:1633-42.

35. Fekry A. Impedance and hydrogen evolution studies on magnesium alloy in oxalic acid solution containing different anions. Int J Hydrog Energy 2010;35:12945-51.

36. Heakal FET, Fekry A, Jibril MAE-B. Electrochemical behaviour of the Mg alloy AZ91D in borate solutions. Corrosion Sci 2011;53:1174-85.

37. Svorc L, Sochr J, Tomcik P, Rievaj M, Bustin D. Simultaneous determination of paracetamol and penicillin $\mathrm{V}$ by square-wave voltammetry at a bare boron-doped diamond electrode. Electrochim Acta 2012;68:227-34.

38. Bard AJ, Faulkner LR. Electrochemical methods: fundamentals and applications. Vol. 2. Wiley New York; 1980.

39. Shariati-Rad M, Irandoust M, Karimi M. Development of a spectrophotometric method for simultaneous determination of dorzolamide and timolol by partial least squares and H-point standard addition method. ACAIJ 2015;11:458-64.

40. Shadoul WA, Gad Kariem EA, Adam ME, Ibrahim KEE. Simultaneous determination of dorzolamide hydrochloride and timolol maleate in ophthalmic solutions using HPLC. Elixir Pharm 2011;38:4060-3.

41. Nagori BP, Maru A, Muysuni P, Gupta S. Method development and its validation for simultaneous estimation of timolol maleate and dorzolamide hydrochloride in as API and in ophthalmic solution dosage form by RPHPLC. J Chem Pharm Res 2011;3:866-74.

\section{How to cite this article}

- Hassan AM Hendawy, Hanan M Elwy, Amany M Fekry. Electrochemical and chemometric determination of dorzolamide and timolol in eye drops using modified multiwall carbon nanotube electrode. Int J Pharm Pharm Sci 2017;9(9):43-50. 